\title{
RANCANG BANGUN QUADROTOR DENGAN KENDALI ROBUST PID UNTUK PEMETAAN SAWAH PRA PANEN
}

\author{
Rendra Dwi Firmansyah ${ }^{1}$, Budi Sumanto ${ }^{2}$, Rella Mareta $^{3}$ \\ 1,2,3 Program Studi Elektronika dan Instrumentasi/Departemen Teknik Elektro dan \\ Informatika/Sekolah Vokasi, Universitas Gadjah Mada, Indonesia \\ Email: ${ }^{1}$ firmansyah_1412@ugm.ac.id, ${ }^{2}$ bs.jogja@gmail.com, ${ }^{3}$ rella.mareta@ugm.ac.id
}

\begin{abstract}
Field mapping is important to know the potential of agricultural productivity in a region. Furthermore, field mapping can also be used to predict crops in a region. The mapping can be done through aerial photographs. Aerial photographs can be performed using manned aerial vehicle as well as unmanned aerial vehicle. Currently, many aerial photographs are taken using unmanned aerial vehicle because the cost is much more affordable than using a manned aerial vehicle. One type of unmanned aircraft used for aerial photographs is quadcopter. However taking aerial photographs using a quadcopter often produces blurry images due to its instability. Instability of the quadcopter is caused by several factors including sensor readings such as IMU, GPS, compass, and barometer, disturbance factors such as angina, and control systems that are less robust to quadcopter characters. To get a stable quadcopter, a control system that matches the quadcopter character and has a resistance to interference is needed. One of the control systems that can be applied to the quadcopter is the Robust PID control system. Reliability of the control system can be seen using ITAE (Integral Time Absolute Error). The smaller the value of ITAE the better the control system. Some tuning methods are done to get the Robust PID control system. The method used in this research is Ziegler Nicols, fine tuned PID controller, and ITAE tuning method. The result of PID constant tuning is then implemented to quadcopter. In this study the response data was obtained by using IMU sensor. The result shows that of the three tuning methods implemented in the quadcopter, the Fine tuning method gives better results than the others.
\end{abstract}

Keywords: mapping, unmanned aerial vehicle, PID, Robust PID, Ziegler Nicols, ITAE Tuning Method

\section{PENDAHULUAN}

Pemetaan lahan didaerah Kulonprogo merupakan salah satu hal penting untuk mendukung agroindustry di Kulonprogo. Hasil pemetaan lahan ini dapat dimanfaatkan untuk berbagai hal diantaranya untuk menghitung luas lahan, melihat sebaran jenis tanaman yang ada di Kulon progo, dan untuk memperkirakan jumlah hasil panen serta masih banyak lagi yang dapat dilakukan dengan hasil pemetaan ini. Pemetaan dapat dilakukan dengan berbagai cara salah satunya adalah melalui foto udara. Pengambilan foto ini dapat dilakukan dengan menggunakan pesawat terbang.

Perkembangan teknologi di bidang kedirgantaraan melahirkan teknologi pesawat tanpa awak atau yang sering disebut dengan UAV(Aerial Unmanned Vehicle) yang dapat digunakan untuk mempermudah pengambilan foto udara. Pesawat tanpa awak mengurangi biaya untuk melakukan pemetaan melalui foto udara yang dulunya diambil melalui pesawat berawak. Pesawat tanpa awak yang digunakan untuk pengambilan gambar dillengkapi dengan kamera. Pesawat tanpa awak ini dibagi menjadi dua jenis yaitu multicopter dan fixed wing. Kedua jenis ini dapat digunakan untuk keperluan pengambilan foto udara.

Pengambilan foto udara memerlukan tingkat kestabilan yang tinggi dari pesawat tanpa awak baik fixed wing maupun multirotor. Jika kestabilannya rendah maka hasil foto udara akan tidak baik 
contohnya terjadi blur sehingga tidak dapat digunakan untuk proses selanjutnya. Untuk mendapatkan kestabilan ini diperlukan sebuah sistem kendali. Sistem kendali membuat pergerakan pesawat tanpa awak lebih stabil. Sistem kendali akan diterapkan di quadcopter adalah sistem kendali robust PID. Sistem kendali ini mampu memberikan tingkat kestabilan yang lebih tinggi dibandingkan dengan PID konvensional sehingga cocok untuk diterapkan pada pengambilan foto udara.

Penelitian ini merancang dan mengimplementasikan sistem kendali Robust PID dan Ziegler Nichols metode 2 pada quadrotor untuk mendapatkan tingkat kestabilan yang tinggi agar mendapatkan foto udara yang baik sehingga dapat digunakan untuk menghitung luas area sawah dengan baik.

Penelitian tentang sistem kendali PID untuk pesawat tanpa awak sudah dilakukan oleh beberapa peneliti. (Lukmana \& Nurhadi, 2015) melakukan penelitian tentang PID yang diterapkan ke UAV jenis quadcopter. Penelitian ini fokus pada respon quadcopter terhadap gangguan dalam yang diterapkan ke roll, pitch, yaw dan ketinggian. Data ketinggian pada penelitian ini didapatkan dari simulasi. Hasil dari penerapan PID pada quadcopter adalah settling time untuk masing-masing parameter. Roll dan pitch memerlukan settling time sebesar 1.419 detik sedangkan yaw mempunyai settling time sebesar 2.327 detik. Altitude hold memiliki settling time sebesar 6.339 detik Ini artinya pada quadcopter akan kembali pada ketinggian yang sama setelah 6 detik dari gangguan yang diberikan.

Penelitian tentang PID untuk quadcopter juga dilakukan oleh (Silva et al., 2016) yang meimplementasikan kendali PID untuk stabilitas posisi (Pitch dan roll) dan kecepatan yaw. Gain PID didapatkan berdasarkan performance dan saturation constraints serta menggunakan Teknik rootLocus. Hasil percobaan menghasilkan stabilitas dan reabilitas yang diinginkan. (Paiva, Soto, Salinas, \& Ipanaqué, 2016) melakukan pemodelan terhadap quadcopter dan merancang sistem kendali PID. Pemodelan dan simulasi dilakukan menggunakan Simulink lalu diimplementasikan ke quadcopter. Simulasi dan percobaan menunjukkan hasil yang memuaskan. Quadcopter tetap dalam keadaan stabil walaupun terkena angin kencang.

Penelitian tentang robust PID dilakukan oleh (Qiao, Luo, \& Xu, 2015) dan menerapkannya ke pemeliharaan limbah air. Metode yang digunakan untuk mendapatkan robust PID adalah teorema Kharitonov dan algoritma genetik. Teorema kharitonov digunakan untuk menyelesaikan masalah nonconvex optimal pada perawatan limbah air. Algoritma genetik digunakan untuk mencari parameter robust PID tanpa menyelesaikan persamaan steady state Riccati. Simulasi menunjukkan bahwa algoritma yang ditawarkan sederhana dan efektif untuk perawatan limbah air yang tidak tentu. Metode baru juga diusulkan oleh (Š \& Kozáková, 2016) untuk diterapkan di single input single output non minimum phase system. Sistem kendali yang ditawarkan oleh penelitian ini adalah nilai overshoot maksimal dan settling time. Algoritma yang dikembangkan menjamin kehandalan desain kendali PID untuk sistem yang tidak pasti.

Robust PID juga dikembangkan untuk bidang tenaga listrik. Robust PID diterapkan ke DC-DC buck converter oleh (Omer, Kumar, \& Surjan, 2016). (Omer et al., 2016) menggunakan algoritma Bat untuk mendapatkan sistem kendali robust PID. DC-DC converter merupakan sistem non linear disebabkan oleh sistem switching. Sistem ini menyebabkan lambatnya DC-DC converter dan menghasilkan defiasi yang besar. Dari simulasi desain kendali PID yang ditawarkan menunjukkan hasil yang memuaskan untuk berbagai variasi beban.

Robust PID juga dapat diterapkan di UAV, seperti yang dilakukan oleh (Hancer, Oner, Sirimoglu, Cetinsoy, \& Unel, 2010). (Hancer et al., 2010) menerapakan robust PID ke tilt wing UAV agar dapat hovering di posisi yang diinginkan dengan angin yang kencang. Angin dan gangguan aerodinamik dimodelkan menggunakan Dryden model. Untuk menambah kehandalan sistem kendali, sistem ini juga dilengkapi dengan pengamat gangguan untuk memperkirakan gangguan yang tidak diketahui. Metode yang diusulkan diujicoba secara simulasi dan percobaan dan menunjukkan hasil yang memuaskan. Kemampuan hovering dari UAV meningkat drastic dengan sistem yang ditawarkan. Posisi UAV tetap berada di titik yang diberikan walaupun dalam kondisi yang berangin.

\section{BAHAN DAN METODE PENELITIAN}

Penelitian ini berfokus pada pembangunan quadrotor dan sistem kendalinya. Quadrotor yang dibangun berukuran f450. Quadrotor ini terdiri dari beberapa bagian yaitu frame, pengendali, attitude 
and heading reference system (AHRS), power supply. Frame yang digunakan adalah frame 4450 tipe $\mathrm{X}$. Pengendali menggunakan pixhawk flight controller. AHRS terdiri dari beberapa sensor yaitu barometer untuk mengukur ketinggian, IMU untuk mengukur pitch, roll dan yaw. Power supply terdiri dari battery dan distribution board yang berfungsi untuk membagikan arus dan tegangan ke actuator. Aktuator terdiri dari 4 motor de jenis brushless. Selain itu quadcopter ini dilengkapi dengan GPS yang berfungsi untuk membaca posisi quadrotor. Transceiver juga dipasang di quadrotor untuk mengirimkan data dari berbagai sensor ke ground section. Implementasi quadrotor yang digunakan dalam penelitian ini ditunjukkan oleh gambar 1 .

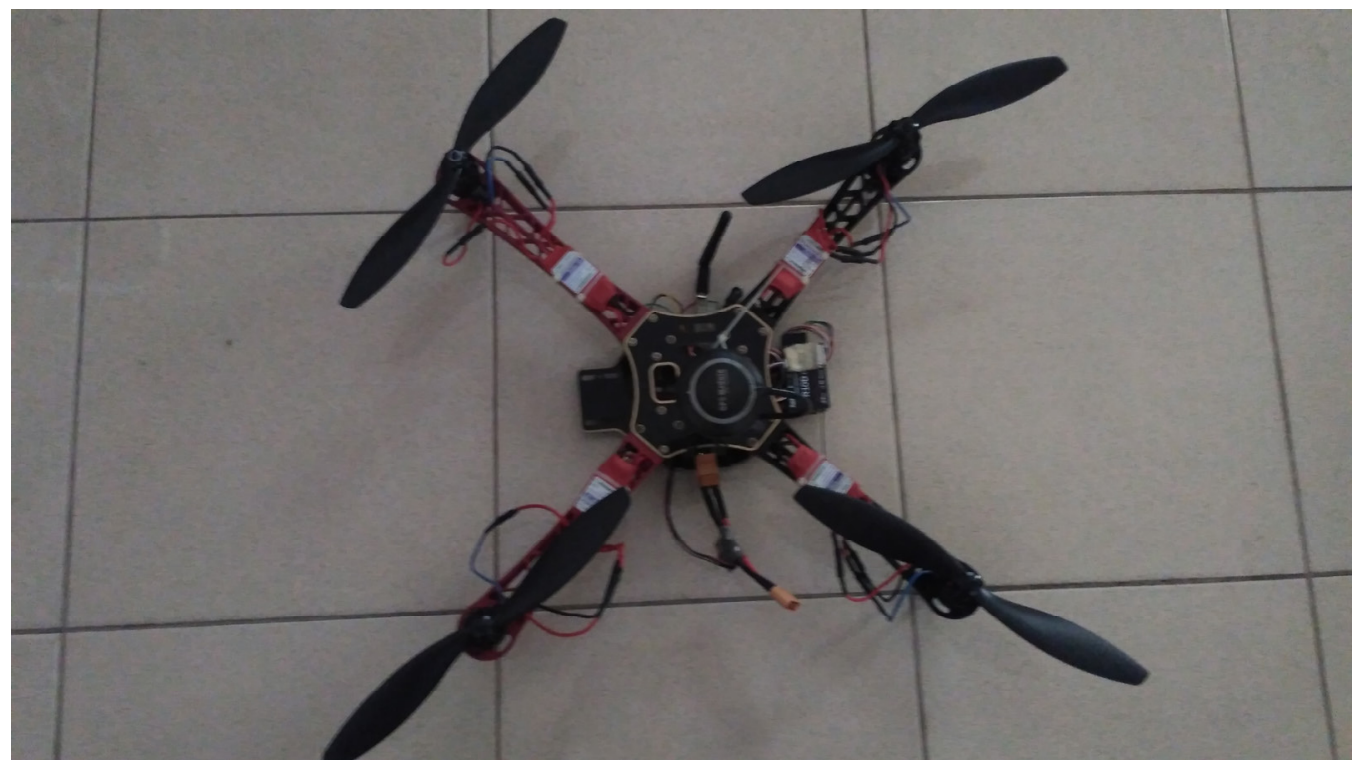

Gambar 1. Prototype Quadrotor

Metode kendali yang digunakan dalam penelitian ini adalah sistem kendali Propotional, Integral, Derivative (PID). Kendali PID dipilih karena dari beberapa penelitian tentang quadrotor PID mempunyai performa yang baik. Sistem kendali ini digunakan untuk menjaga kestabilan quadrotor. Tingkat kestabilan quadrotor ini dapat dilihat dari pembacaan sensor IMU. Sensor ini memberikan informasi pembacaan Roll Pitch, dan yaw. Pembacaan Pitch, roll dan yaw ditunjukkan oleh gambar 2.

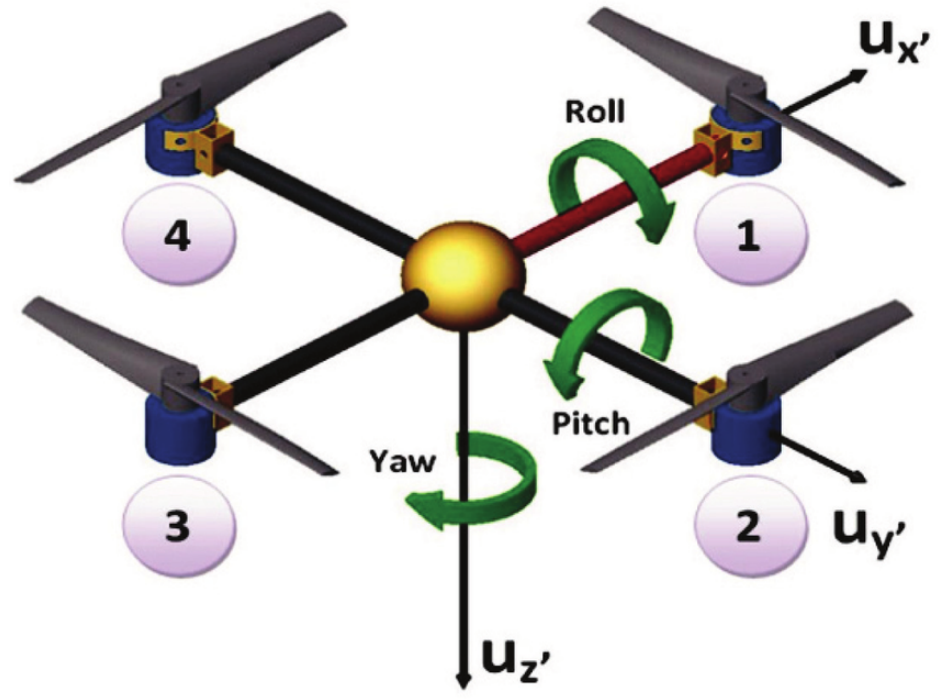

Gambar 2. Pitch, Roll dan Yaw

Quadrotor dianggap stabil jika pembacaan pitch dan roll bernilai nol atau dengan kata lain set point dari quadrotor ini adalah 0 . Nilai set point ini akan dikurangi dengan nilai pembacaan sensor IMU. Hasil pengurangan ini adalah nilai error yang digunakan untuk menghitung sinyal kendali pada 
masing-masing bagian. Perhitungan sinyal kendali ini melibatkan nilai konstanta propotional, integral dan derivative. Blok diagram kendali untuk quadrotor ini ditunjukkan oleh gambar 3 .

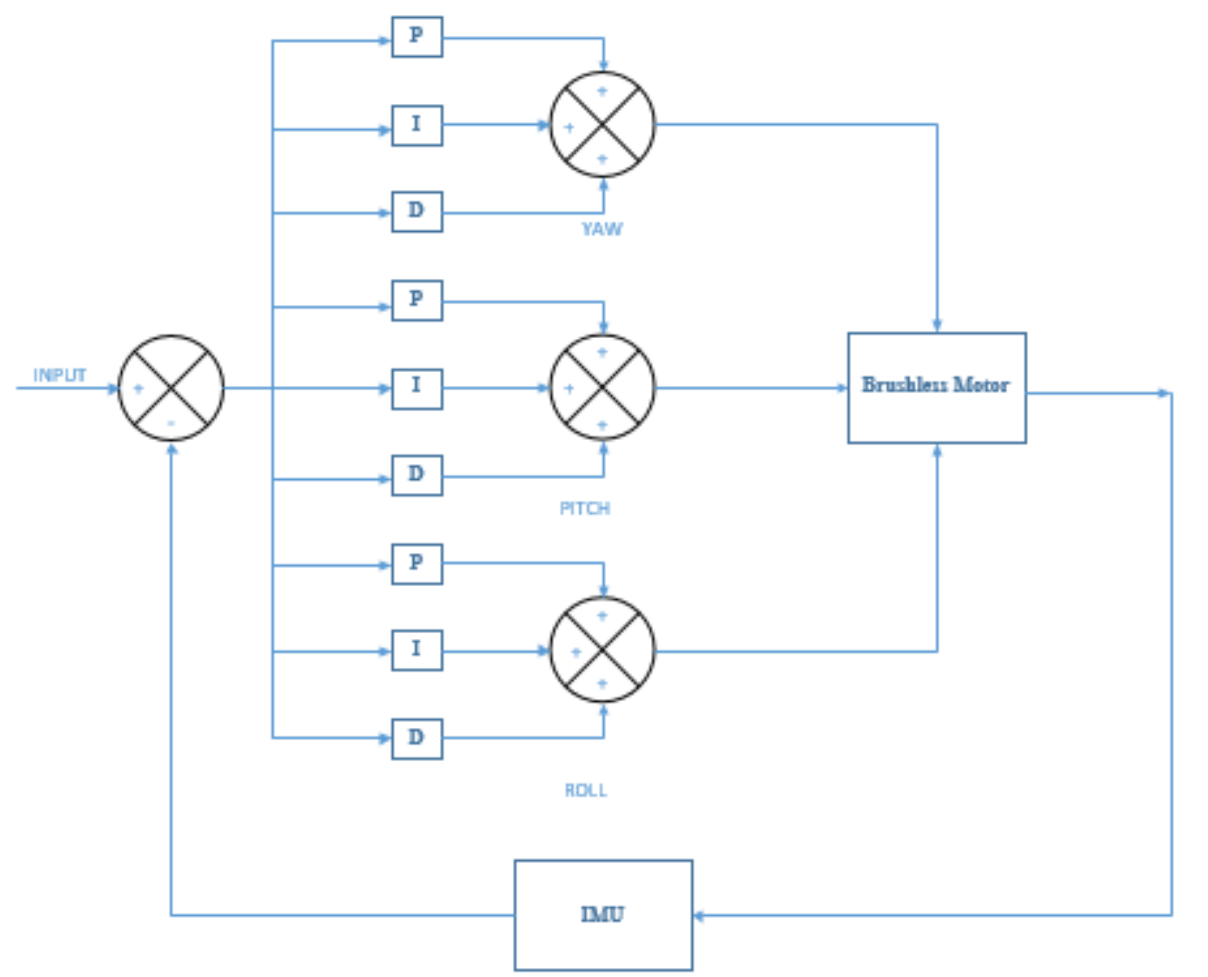

Gambar 3. Diagram blok sistem kendali

Kestabilan quadrotor juga tergantung dari nilai konstanta PID yang didapatkan dari experimen yang diberi istilah tuning. Tuning dilakukan dengan dua cara yaitu autotuning dan manual tuning. Autotuing dilakukan dengan menerbangkan quadrotor dan quadrotor akan melakukan tuning secara otomatis. Manual tuning dilakukan dengan mengganti nilai konstanta PID kemudian menerbangkan quadrotor dan dilihat performa terbang dari quadrotor.

\section{HASIL DAN PEMBAHASAN}

Percobaan dilakukan di daerah lapang dan dilakukan beberapa kali uji terbang. Ada nilai konstanta PID yang diujikan. Nilai autotuning dan manual tuning, masing-masing nilai dilihat performa terbangnya dan diambil kesimpulan apakah nilai tersebut sudah menghasilkan performa terbang yang baik. Nilai-nilai PID yang diujikan dalam penelitian ini ditunjukkan oleh tabel 1 .

\section{Tabel 1. Konstanta PID}

\begin{tabular}{c|c|c|c|c|c|c}
\hline \multirow{2}{*}{ No } & \multicolumn{3}{|c|}{ PITCH } & \multicolumn{3}{c}{ ROLL } \\
\cline { 2 - 7 } & $\mathrm{P}$ & $\mathrm{I}$ & $\mathrm{D}$ & $\mathrm{P}$ & $\mathrm{I}$ & $\mathrm{D}$ \\
\hline 1 & 0.09128 & 0.09128 & 0.00698 & 0.090 & 0.090 & 0.004 \\
\hline 2 & 0.75 & 0.75 & 0.004 & 0.75 & 0.75 & 0.004 \\
\hline 3 & 0.1 & 0.010 & 0.001 & 0.1 & 0.01 & 0.001 \\
\hline 4 & 0.125 & 0.020 & 0.001 & 0.125 & 0.020 & 0.001 \\
\hline 5 & 0.125 & 0.050 & 0.001 & 0.125 & 0.050 & 0.001 \\
\hline 6 & 0.125 & 0.050 & 0.007 & 0.125 & 0.050 & 0.007 \\
\hline
\end{tabular}

Masing-masing nilai PID diujikan ke quadrotor, dan hasil uji terbang konstanta PID no 1 ditunjukkan oleh gambar $4 \mathrm{a}$ dan $4 \mathrm{~b}$. Pada gambar $4 \mathrm{a}$ dan $4 \mathrm{~b}$ masih banyak terjadi ripple. Sehingga performanya belum stabil baik untuk roll maupun pitch. 


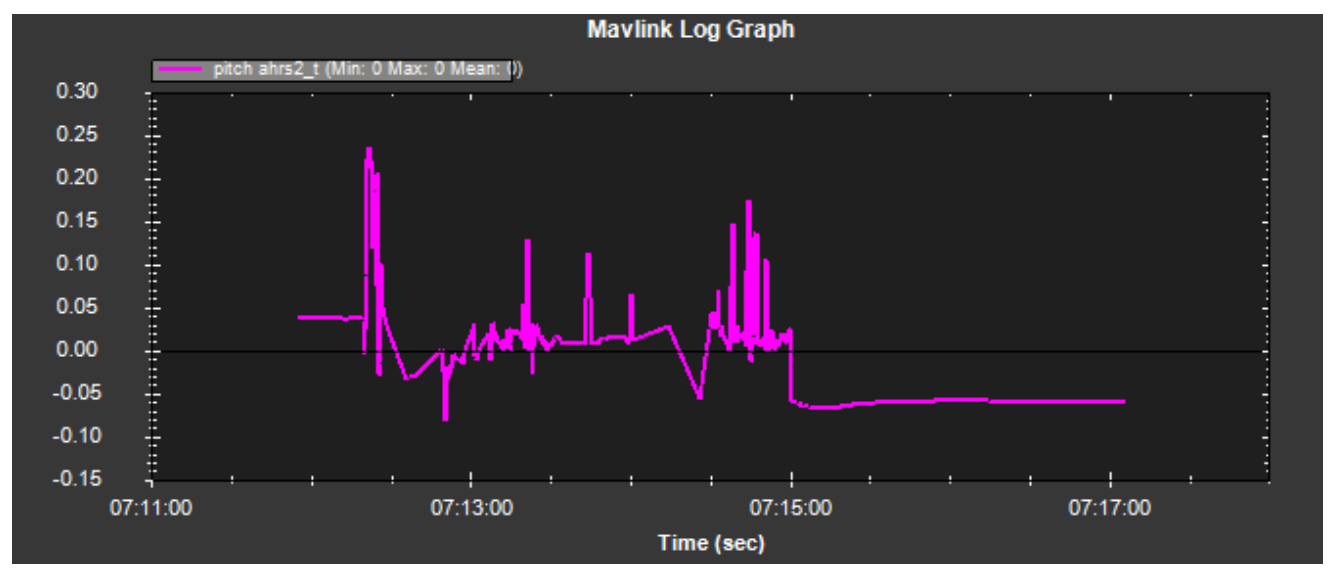

Gambar 4a. Pitch PID 1

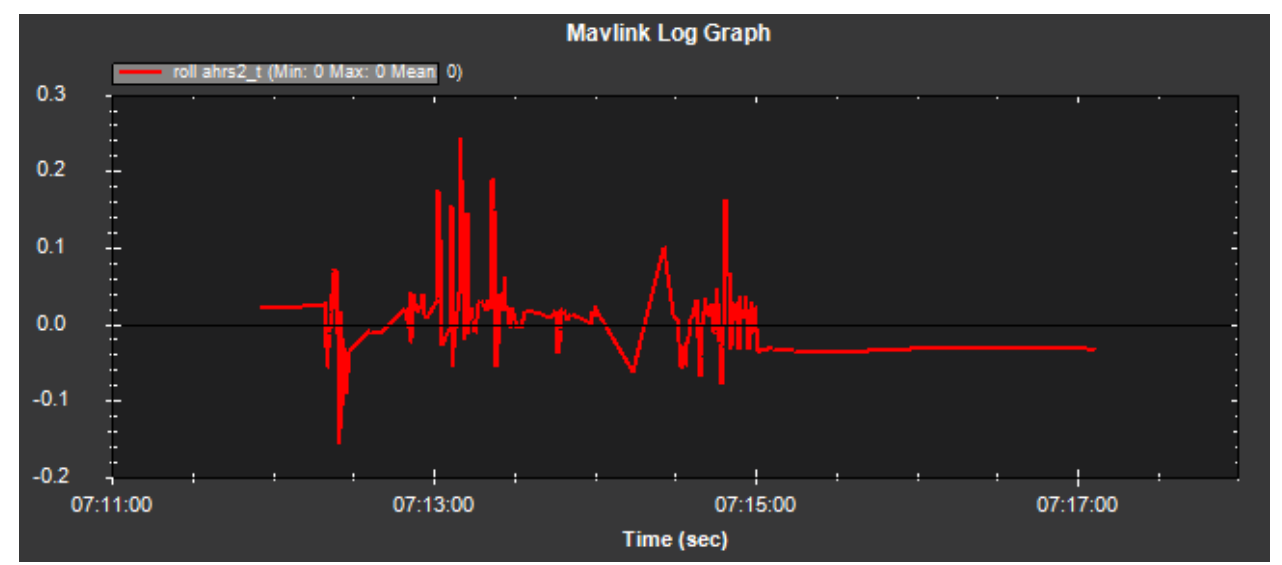

Gambar 4b. ROLL PID 1

Gambar 5a dan 5b menunjukkan performa quadrotor dengan konstanta PID 2. Terlihat pada gambar ini baik PITCH dan ROLL masih tidak stabil.

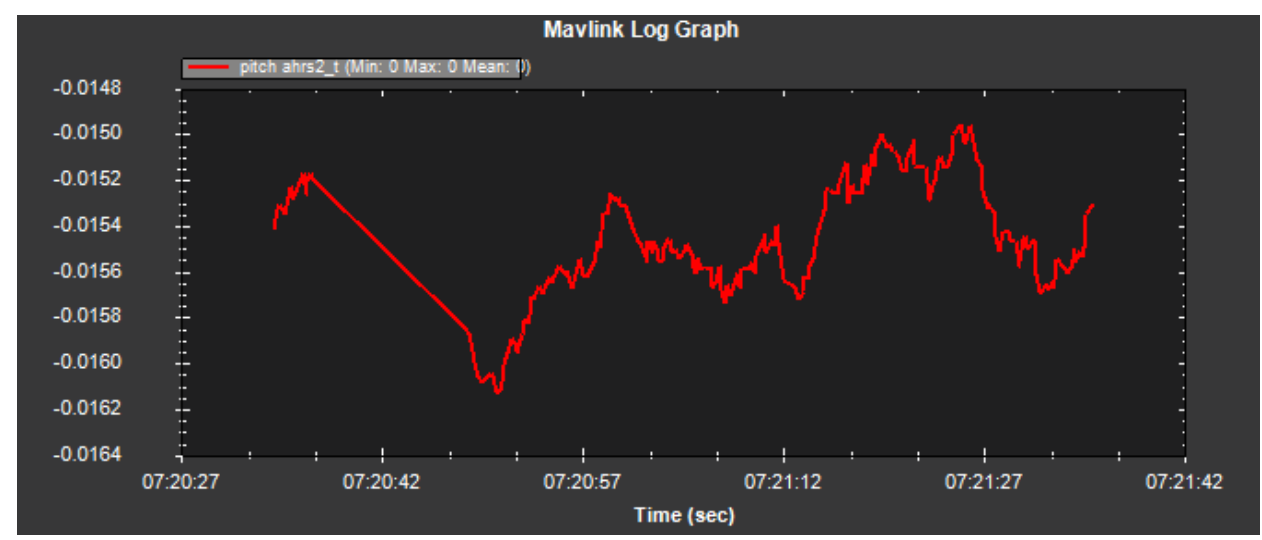

Gambar 5a. Pitch PID 2 


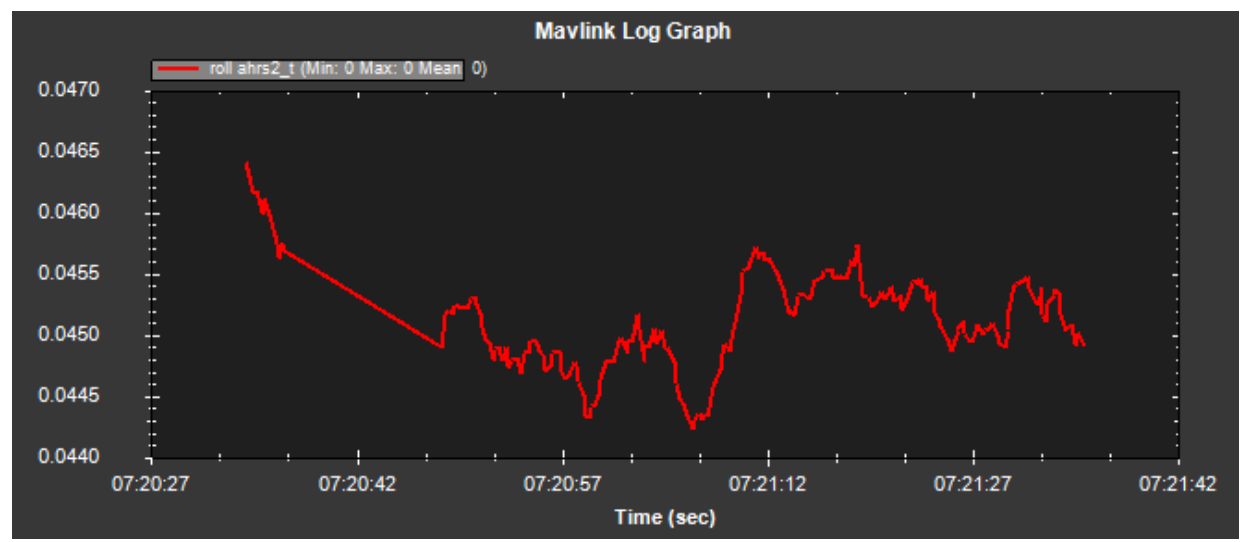

Gambar 5b. ROLL PID 2

Gambar 6a dan 6b menunjukkan performa quadrotor dengan konstanta PID 3. Terlihat pada gambar ini baik PITCH dan ROLL sudah stabil. Ketika diberi perintah dari remote untuk bergerak kedepan dan kesamping quadrotor dapat langsung kembali ke set point.

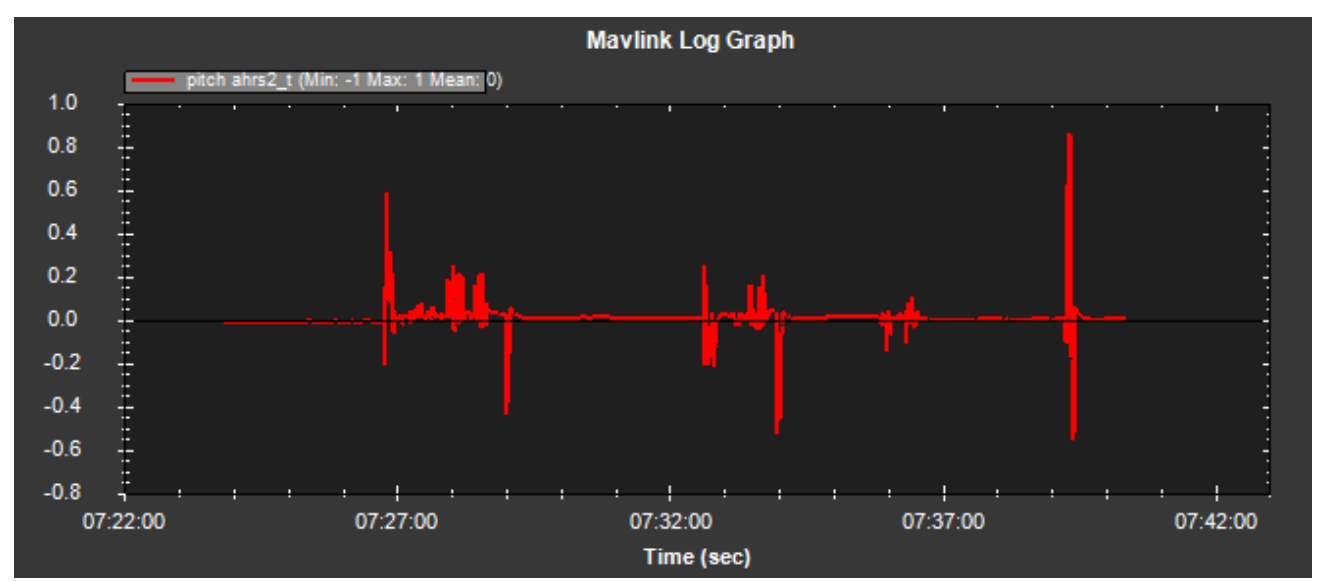

Gambar 6a. Pitch PID 3

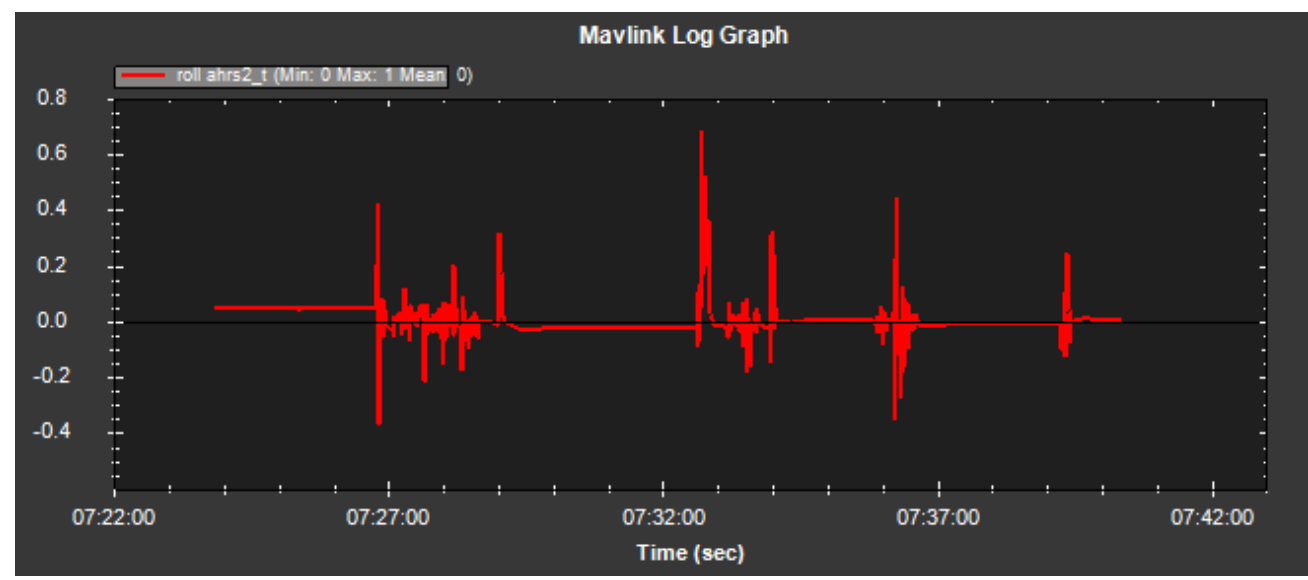

Gambar 6b. ROLL PID 3

Gambar 7a dan 7b menunjukkan performa quadrotor dengan konstanta PID 4. Terlihat pada gambar ini baik PITCH dan ROLL sudah stabil. Ketika diberi perintah dari remote untuk bergerak kedepan dan kesamping quadrotor dapat langsung kembali ke set point tetapi tidak secepat pada PID 3 


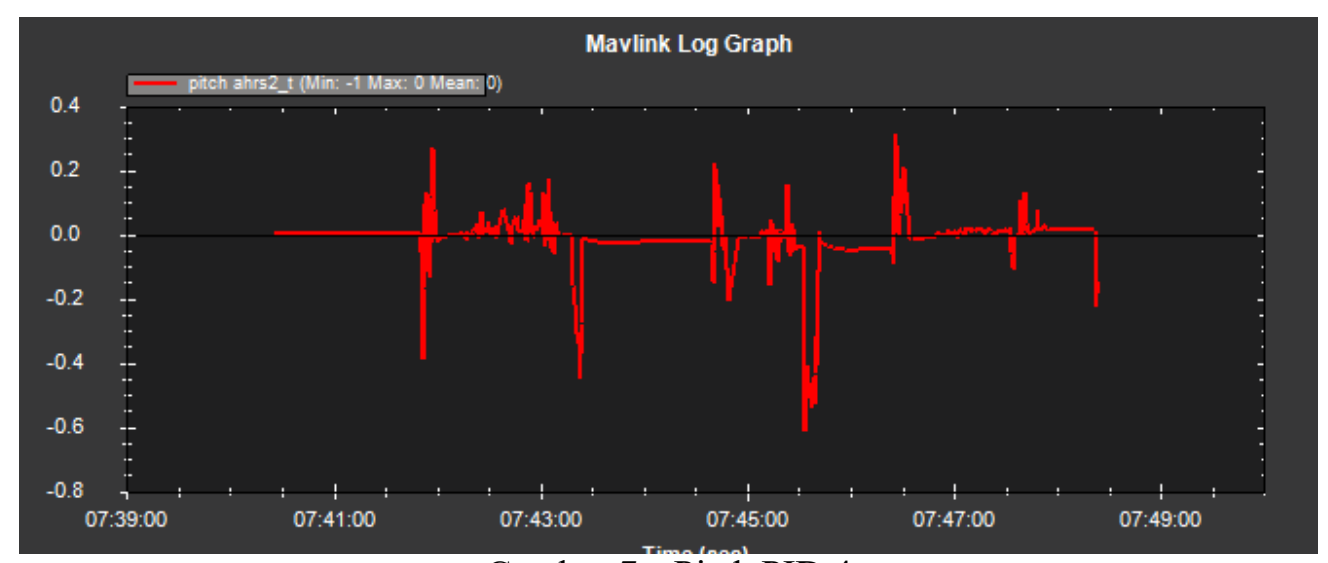

Gambar 7a. Pitch PID 4

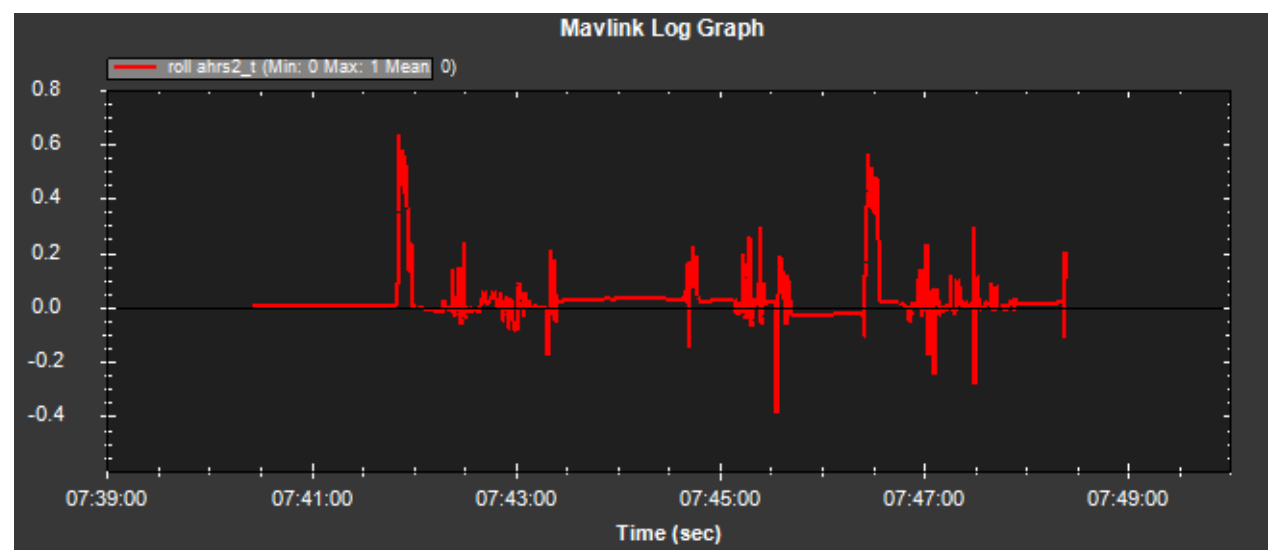

Gambar 7b. ROLL PID 4

Gambar 8a dan 8b menunjukkan performa quadrotor dengan konstanta PID 5. Terlihat pada gambar ini baik PITCH dan ROLL sudah stabil. Ketika diberi perintah dari remote untuk bergerak kedepan dan kesamping quadrotor dapat langsung kembali ke set point tetapi tidak secepat pada PID 3

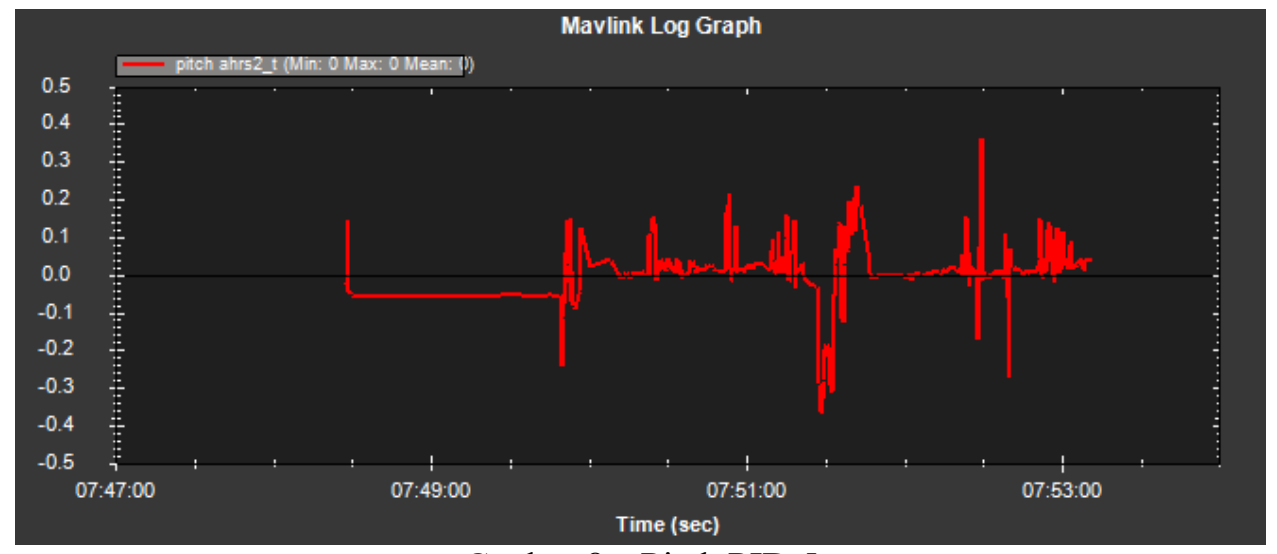

Ganbar 8a. Pitch PID 5 


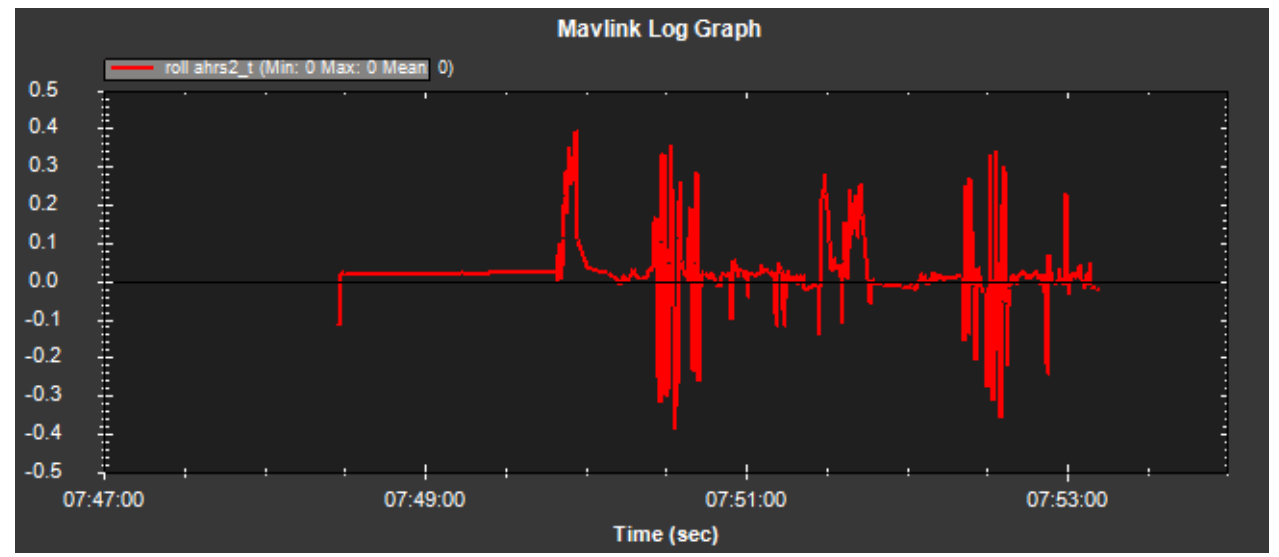

Gambar 8b. ROLL PID 5

Gambar 9a dan 9b menunjukkan performa quadrotor dengan konstanta PID 6. Terlihat pada gambar ini baik PITCH dan ROLL sudah stabil. Ketika diberi perintah dari remote untuk bergerak kedepan dan kesamping quadrotor dapat langsung kembali ke set point tetapi tidak secepat pada PID 3

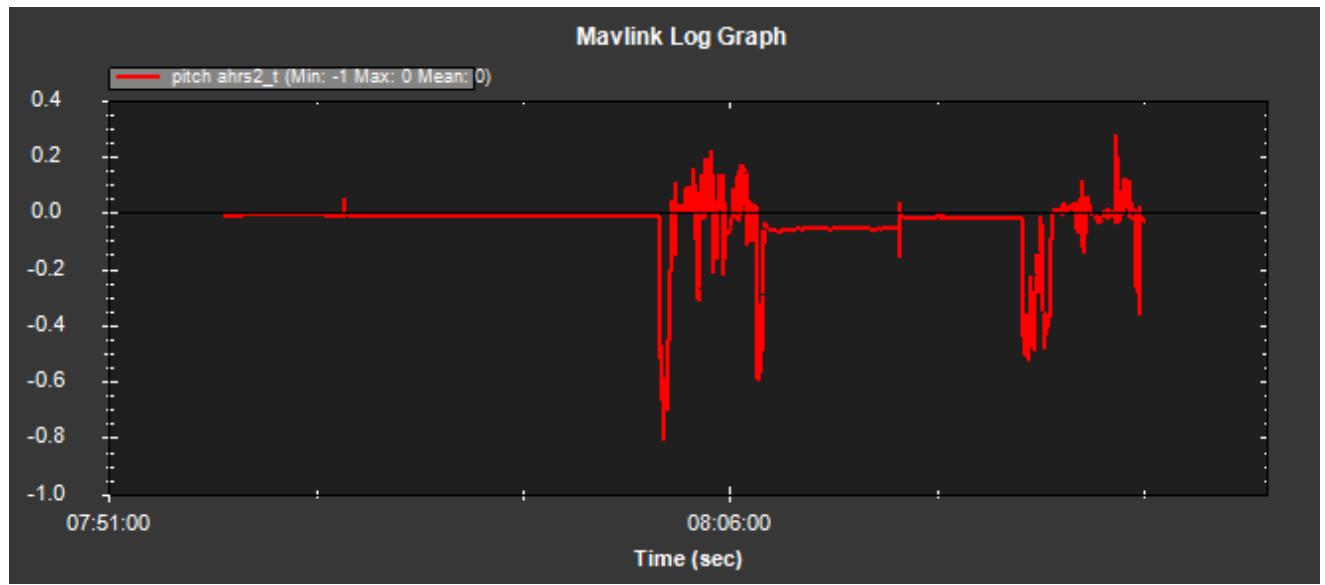

Gambar 9a. Pitch PID 6

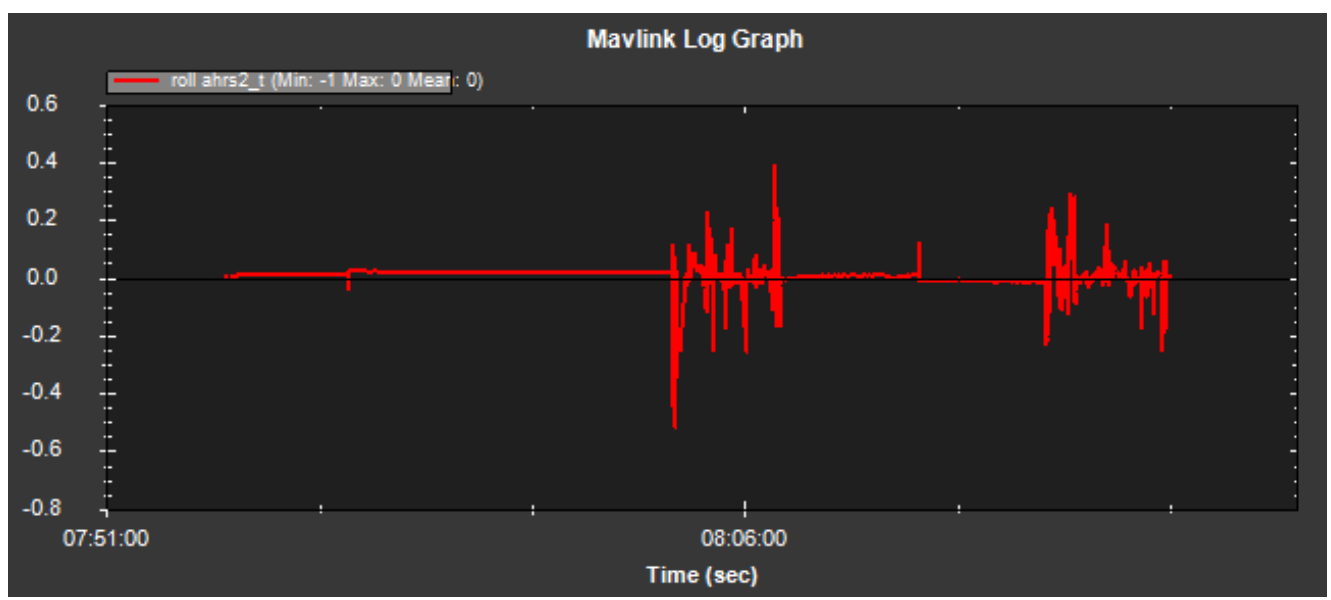

Gambar 9b. ROLL PID 6

\section{KESIMPULAN}

Sistem kendali PID telah dimplementasikan pada purwarupa quadrotor dan menghasilkan performa terbang yang cukup baik. Nilai konstanta PID yang baik untuk quadrotor ini adalah $\mathrm{P}=0.1$, $\mathrm{I}=0.010, \mathrm{D}=0.001$. 


\section{DAFTAR PUSTAKA}

Hancer, C., Oner, K. T., Sirimoglu, E., Cetinsoy, E., \& Unel, M. (2010, 7-10 Nov. 2010). Robust hovering control of a quad tilt-wing UAV. Paper presented at the IECON 2010 36th Annual Conference on IEEE Industrial Electronics Society.

Lukmana, M. A., \& Nurhadi, H. (2015, 15-17 Oct. 2015). Preliminary study on Unmanned Aerial Vehicle (UAV) Quadcopter using PID controller. Paper presented at the 2015 International Conference on Advanced Mechatronics, Intelligent Manufacture, and Industrial Automation (ICAMIMIA).

Omer, P., Kumar, J., \& Surjan, B. S. (2016, 4-6 July 2016). Design of robust PID controller for Buck converter using Bat algorithm. Paper presented at the 2016 IEEE 1st International Conference on Power Electronics, Intelligent Control and Energy Systems (ICPEICES).

Paiva, E., Soto, J., Salinas, J., \& Ipanaqué, W. (2016, 19-21 Oct. 2016). Modeling, simulation and implementation of a modified PID controller for stabilizing a quadcopter. Paper presented at the 2016 IEEE International Conference on Automatica (ICA-ACCA).

Qiao, X., Luo, F., \& Xu, Y. (2015, 26-28 Nov. 2015). Synthesis of robust PID controllers via stability methods for a wastewater treatment. Paper presented at the 2015 Sixth International Conference on Intelligent Control and Information Processing (ICICIP).

Š, B., \& Kozáková, A. (2016, 2-5 Feb. 2016). A new robust PID controller design methodology for systems with unstable zero. Paper presented at the 2016 Cybernetics \& Informatics (K\&I).

Silva, M. F., Ribeiro, A. C., Santos, M. F., Carmo, M. J., Honório, L. M., Oliveira, E. J., \& Vidal, V. F. (2016, 13-15 Oct. 2016). Design of angular PID controllers for quadcopters built with low cost equipment. Paper presented at the 2016 20th International Conference on System Theory, Control and Computing (ICSTCC). 